Research Article, Issue 1
AMECJ

\title{
Cloud point-dispersive liquid-liquid microextraction for preconcentration and separation of mercury in wastewater samples by methylsulfanyl thiophenol material
}

\author{
Azwan Morni and Seyed Mojtaba Mostafavib ${ }^{\mathrm{b}, *}$ \\ a Department of Chemometrics, International Institute of Theoretical and Computational Chemistry, India \\ ${ }_{b, *}^{*}$ Department of Chemistry, Iranian-Australian Community of Science, Hobart, Tasmania, Australia
}

\begin{abstract}
A R T I C L E I N F O:
Received 14 Dec 2019

Revised 12 Feb 2020

Accepted 4 Mar 2020

Available online 30 Mar 2020

Keywords:

Mercury,

Wastewaters,

Methylsulfanyl thiophenol,

Ionic liquid,

Cloud point dispersive liquid-

liquid microextraction
\end{abstract}

\begin{abstract}
A B S T R A C T
A efficient method based on 4-methylsulfanyl thiophenol (MSTP, $\mathrm{C}_{7} \mathrm{H}_{8} \mathrm{~S}_{2}$ ) and ionic liquid ([BMIM] $\left.\left[\mathrm{PF}_{6}\right]\right)$ was used for mercury (Hg) separation and preconcentration from wastewater of petrochemical industries. The 0.01 mile molar of MSTP, $80 \mathrm{mg}$ of [BMIM] $\left[\mathrm{PF}_{6}\right]$ was diluted with $0.2 \mathrm{~mL}$ of ethanol (Et 98\%). The mixture was injected to $10 \mathrm{~mL}$ of wastewater samples, shacked by ultrasonic bath for 5.0 min and cloudy solution was achieved by ionic liquid micelles at $\mathrm{pH}=7.0$. The mercury ions was complexed with MSTP and extracted on micelles (IL/Et) by cloud point dispersive liquidliquid microextraction (CP-DLLME) at $50^{\circ} \mathrm{C}$ before determined by cold vapor atomic absorption spectrometry (CV-AAS). The favorite extraction for mercury with low LOD $\left(15 \mathrm{ng} \mathrm{L}^{-1}\right)$ and good linear rages $\left(0.05-6.2 \mu \mathrm{g} \mathrm{L}^{-1}\right)$ was achieved $(\mathrm{RSD}<5 \%)$. The main parameters such as, $\mathrm{pH}$, sample volumes, amount of MSTP, amount of IL and ultra-sonic time were optimized. The method validated by spiking samples and certified reference material (CRM, NIST) in water sample.
\end{abstract}

\section{Introduction}

Mercury compounds (Hg, R-Hg) as toxic pollutants enter to environment from wastewater factories and cause different disease in humans. There are three forms of $\mathrm{Hg}$ ( $\mathrm{Hg}^{0}, \mathrm{Hg}$ (II), R-Hg) which was used in different industries [1]. The high exposure of inorganic mercury damaged the human organs such as renal, liver and CNS [2]. Although the exposure to organic mercury or fish food can be created an main problem in blood brain barrier (BBB) and cortex of brain but is weaker than inorganic compounds

Corresponding Author: $\mathrm{M}^{*}$

E-mail: mojtabamostafavi@gmail.com https://doi.org/10.24200/amecj.v3.i01.97
[3]. The hazardous defect in humans organs such as, CNS, respiratory, cells, renal and liver caused to different diseases, hypertension, chromosomal aberrations, tremor and MS [4]. So, as high toxicity, mercury determination in wastewaters is very important as industries samples. The mercury concentration in water is less than $6 \mu \mathrm{g} \mathrm{L}^{-1}$ [5] and in blood is less than 1-2 $\mu \mathrm{g} \mathrm{dL}^{-1}$ [6]. So, the reliable, accurate and fast analytical methods must be used for wastewater samples. Among different analytical methods cold vapor atomic absorption spectrometry (CV-AFS) has been widely used for mercury determination in water samples due to simple, lower LOD and good sensitivity [7]. But, 
as low concentration of $\mathrm{Hg}$ and high interferences ions in wastewaters, the preconcentration and extraction processes must be done [8,9]. Recently, different extraction or microextraction mechanisms were used for this purpose. The micro-solid phase extraction ( $\mu$-SPE) [10]. CPE [11], LLME based on ionic liquids [12], The DLLME and LLME are a strategy promotes the complexation processes between metal and ligand [13]. CP-DLLME technique can be assisted by ultrasonic accessory [14]. Solidified floating organic drop DLLME (SFO-DLLME) was developed by Kocurov et al and many other techniques introduced by liquid extraction procedure [15-22]. The cloud point extraction (CPE) caused to two phases for solution by temperature. The surfactants such as T-X100 were used for metal separation by clouding phenomena (S-CPE). The S-CPE has many advantages as compared to traditional extraction. The two components, salt and surfactant solutions separate into immiscible phases [23]. The metal mineral can analysis by different methods such as electrochemistry, ionic liquids and nano sorbents [24]. In the presence of salt, ionic liquids and surfactants self assemble in liquid phase at special temperature change to micelles [25-28]. Many metals interacted to micelles and so preconcentrated into the surfactant-rich phase. The aim of this study is to develop a new analytical method for rapid preconcentration and determination of trace mercury in wastewater samples based on the combination of CP-DLLME technique coupled to

Table 1. The CV-AAS conditions for mercury analysis

\begin{tabular}{|c|c|}
\hline Features & Value \\
\hline Linear range, $\mu \mathrm{g} \mathrm{L}^{-1}$ & $1-62$ \\
\hline Wavelength, nm & 253.7 \\
\hline Lamp current, mA & 3.0 \\
\hline Slit, nm & 0.5 \\
\hline Mode & Peak Area \\
\hline $\mathrm{HCl}$ carrier solution $37 \%$, $\mathrm{mol} \mathrm{L}^{-1}$ & 3.0 \\
\hline $\mathrm{NaBH}_{4}$ reducing agent, $\%(\mathrm{~m} / \mathrm{v})$ & $0.5($ in $0.5 \% \mathrm{w} / \mathrm{v} \mathrm{NaOH})$ \\
\hline Argon flow rate, $\mathrm{mL} \mathrm{min}^{-1}$ & $10-15$ \\
\hline Sample flow rate, $\mathrm{mL} \mathrm{min}^{-1}$ & $3-5$ \\
\hline Reagent flow rate, $\mathrm{mL} \mathrm{min}^{-1}$ & $4-6$ \\
\hline
\end{tabular}

CV-AAS. Ionic liquid of [BMIM] $\left[\mathrm{PF}_{6}\right]$ dispersed in ethanol was used as trapping solvent for separation of MSTP from liquid phase. All factors which were affected on mercury extraction were studied and performance of the proposed method was validated.

\section{Experimental}

\subsection{Apparatus and Reagents}

Mercury was determined by atomic absorption spectrometer with a cold vapor accessory (GBC 932, CV-AAS, AUS), deuterium-lamp (UV), $\mathrm{Hg} \mathrm{HCL}$, and a unit of circulating cooling. The conditions of CV-AAS were shown in Table 1. The $\mathrm{pH}$ values of the solutions were measured by a digital $\mathrm{pH}$ meter Metrohm (744, Swiss). A Hettich centrifuge (Germany) and an ultra sonic accessory (Tecno-GAZ, Germany) were used. All reagents with high purity and analytical grade were purchased from Merck (Germany). All standard solutions were prepared with deionized water (DW) from Millipore (USA). The Hg (II) standard stock solution (1000 ppm in $1 \% \mathrm{HNO}_{3}$ ) was prepared from Sigma Aldrich, Switzerland. The experimental standard mercury were prepared daily by diluting of DW. The standards from 0.05- $6.2 \mathrm{ppb}$ were freshly prepared and stored in a fridge $\left(4^{\circ} \mathrm{C}\right)$. A $0.5 \%(\mathrm{w} / \mathrm{v})$ sodium borohydride $\left(\mathrm{NaBH}_{4}\right)$ was prepared daily by dissolving an appropriate amount of $\mathrm{NaBH}_{4}$ in $0.5 \%(\mathrm{w} / \mathrm{v})$ of $\mathrm{NaOH}$ and used for hydration of mercury $\left(\mathrm{HgH}_{2}\right)$. 1-Benzyl-3-methylimidazolium hexafluorophosphate $\geq 97.0 \% \quad$ ([BMIM] $\left[\mathrm{PF}_{6}\right]$; CASN: 39447), 1-Butyl-2,3-dimethylimidazolium hexafluorophosphate (CASN: 70869), 1,3-Diethoxyimidazolium hexafluorophosphate $\geq$ 97\% (CASN: 688649), 1,3-Dimethoxyimidazolium hexafluorophosphate 98\% (CASN: 690821) were purchased from Sigma-Aldrich ,Germany. The 4-methylsulfanyl thiophenol (CAS N: 1122-97-0, $96 \%$, MSTP, $\mathrm{C}_{7} \mathrm{H}_{8} \mathrm{~S}_{2}$ ) was purchased from Sigma Aldrich, Germany. The $\mathrm{pH}$ adjusted to 6.5 by using sodium phosphate $\left(\mathrm{Na}_{2} \mathrm{HPO}_{4} / \mathrm{NaH}_{2} \mathrm{PO}_{4}\right.$, $)$ as $\mathrm{pH}$ of 5.8-8.2. All the laboratory glasses were cleaned and washed by nitric acid and DW. 


\subsection{Sampling}

Samples of wastewater (paint factory, Tehran, Iran), wastewater ( industrial factories, Jajrood, Iran), oil company wastewater (Tehran, Iran) and chemical factory wastewater (Tehran, Iran) collected and filtered $(0.45 \mu \mathrm{m})$ with polyethylene tubes and cellulose membrane (CMF), respectively before we used. The $\mathrm{pH}$ was tuned up to 7.0 with phosphate buffer solution. Then, the cloud point dispersive liquidliquid microextraction (CP-DLLME) procedure was used for mercury extraction and determination in wastewater samples. The standard reference materials NIST NIST-SRM 1641e (total mercury in water) from the National Institute of Standard and Technology (NIST, Gaithersburg, USA) were also analyzed in a similar manner according to the general procedure.

\subsection{CPE procedure}

A simple procedure based on MSTP was used for separation of mercury ions from wastewater samples by cloud point dispersive liquid-liquid microextraction (CP-DLLME) at $50^{\circ} \mathrm{C}$. The 10 $\times 10^{-6} \mathrm{~mol} \mathrm{~L}^{-1}$ of MSTP solution, $80 \mathrm{mg}$ of [BMIM] $\left[\mathrm{PF}_{6}\right]$ and $0.2 \mathrm{~mL}$ of ethanol was injected to $10 \mathrm{~mL}$ of wastewater samples. The samples were shacked by ultrasonic bath for 10 min and cloudy solution was achieved by ionic liquid/ethanol micelles at $\mathrm{pH}=7.0$. The $\mathrm{pH}$ of sample adjusted with $1 \mathrm{~mL}$ of buffer solution up to 7.0 which was added to 10 $\mathrm{mL}$ of wastewater samples. Based on ionic liquid/ ethanol micelles, the cloud point extraction (CPE) for $\mathrm{Hg}(\mathrm{II})$ ions was obtained by adding, $0.08 \mathrm{~g}$ $(120 \mu \mathrm{L})$ of [BMIM] $\left[\mathrm{PF}_{6}\right]$ and $0.2 \mathrm{~mL}$ of ethanol as a dispersive solvent in wastewater samples. For optimizing and recovery, $10 \mathrm{~mL}$ of $0.02,0.1,0.5$. 1.0, 3.0 and $6.0 \mu \mathrm{g} \mathrm{L}{ }^{-1} \mathrm{Hg}(\mathrm{II})$ as working standard solution was prepared and used by CP-DLLME procedure. The cloudy solution was shaken for $5.0 \mathrm{~min}$ by ultrasonic shaking at $50{ }^{\circ} \mathrm{C}$. In order to separate the phases, the turbid solution was centrifuged for $5.0 \mathrm{~min}$ at $4500 \mathrm{rpm}$ and the liquid phase was removed with an auto-sampler of $10 \mathrm{~mL}$. $\mathrm{Hg}(\mathrm{II})$ ions back-extracted from [BMIM] $\left[\mathrm{PF}_{6}\right]$ with $0.5 \mathrm{~mL}$ of nitric acid $(1.5 \mathrm{M})$ and after dilution with DW up to $1 \mathrm{~mL}$ determined by CV-AAS (Fig.1). The blank solutions proceeded the same way and are used for the preparation of the calibration solutions and for measurement of the blanks. The extraction mercury based on MSTP-CP-DILLME method was shown in Table 2.

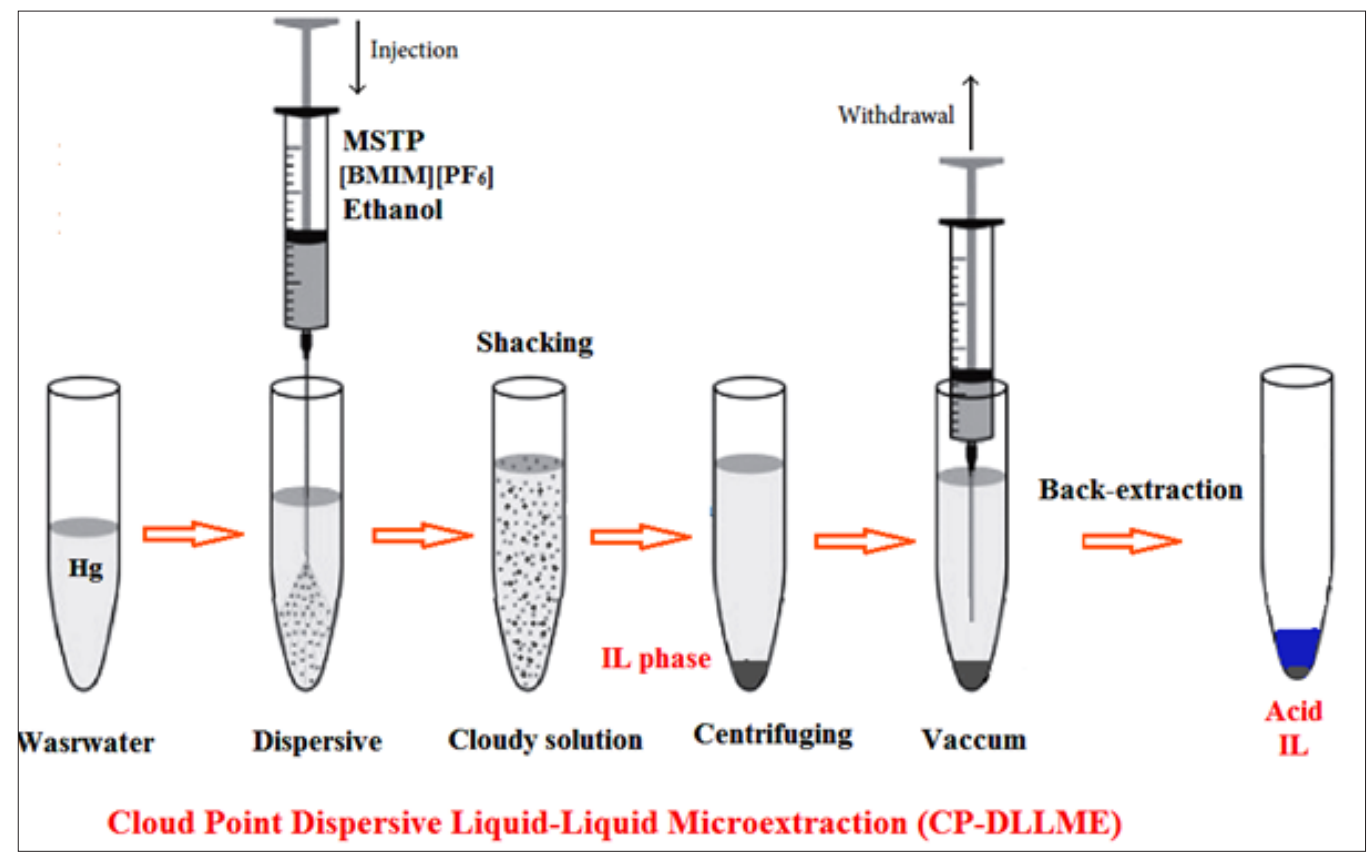

Fig. 1. The mercury extraction based on MSTP by cloud point dispersive liquid-liquid microextraction (CP-DLLME) 
Table 2 The characteristics of the developed MSTP-CP-DILLME method for mercury extraction in wastewater samples $\left(10 \mathrm{~mL}, \mathrm{pH}=6.5,0.02-6.2 \mu \mathrm{g} \mathrm{L}^{-1}\right)$

\begin{tabular}{lcc}
\hline Parameter (Inter-day) & Wastewater sample & Standard sample \\
\hline $\mathrm{PF}^{\mathrm{a}}$ & 9.8 & 10.2 \\
$\mathrm{LOD}^{\mathrm{b}}\left(\mathrm{n}=10, \mathrm{ng} \mathrm{L}^{-1}\right)$ & 15.8 & 15.2 \\
$\mathrm{LOQ}\left(\mathrm{n}=10, \mu \mathrm{g} \mathrm{L}^{-1}\right)$ & 0.053 & 0.048 \\
$\mathrm{RSD}^{\mathrm{c}}(\mathrm{n}=6, \%)$ & 2.4 & 2.2 \\
Linear range $\left(\mu \mathrm{g} \mathrm{L}^{-1}\right)$ & $0.05-6.3$ & $0.05-6.1$ \\
Working Range $\left(\mu \mathrm{g} \mathrm{L}^{-1}\right)$ & $0.05-14.5$ & $0.05-14.2$ \\
Correlation coefficient & 0.9993 & 0.9997 \\
\hline
\end{tabular}

${ }^{\mathrm{a}}$ Preconcentration factor, ${ }^{\mathrm{b}}$ Limit of detection , ${ }^{\mathrm{c}}$ Relative standard deviation.

\section{Results and discussion}

\subsection{Optimization of $\mathrm{pH}$}

The effect of $\mathrm{pH}$ on complexation of mercury ions based on MSTP was investigated in different $\mathrm{pH}$ from 2 to 10 for $0.05 \mu \mathrm{g} \mathrm{L} \mathrm{L}^{-1}, 0.5 \mu \mathrm{g} \mathrm{\textrm {L } ^ { - 1 }}, 6.2 \mu \mathrm{g}$ $\mathrm{L}^{-1} \mathrm{Hg}(\mathrm{II})$ as a LLOQ, MLOQ and ULOQ ranges. The complexation was strongly depended on the $\mathrm{pH}$ sample and subsequently caused to increase the extraction efficiency of mercury in wastewater samples. Based on results, the maximum extraction efficiency for mercury was obtained at $\mathrm{pH}=7.0$ and the recovery were below $5 \%$ in acidic or basic $\mathrm{pH}$. Therefore, the $\mathrm{pH}=6-8$ was selected as optimum $\mathrm{pH}$ for mercury extraction from wastewater samples by the developed MSTP-CP-DILLME method with high recovery (Fig. 2). In $\mathrm{pH}=6-10$, the sulfur (-) has negative charge but mercury based on positive charge $(+)$ can be complexed with sulfur in $\mathrm{pH}$ more of 6 and less than 8 . The results showed the maximum extraction was achieved at $\mathrm{pH}=7$ for mercury by coordinating covalent bond of sulfur $\left(\mathrm{Hg}^{2+}---: \mathrm{S}^{2-}\right)$.

\subsection{Optimization of ionic liquid}

By procedure, the wastewater samples were shaked by ultrasonic bath for 10 min and cloudy solution was achieved by ionic liquid/ethanol micelles at $\mathrm{pH}=7.0$. So the kind and amount of ionic liquid has critical role as generation micelles in liquid phase and extraction process by MSTP-CP-DILLME method. For this purpose, different ILs such as, 1-Benzyl-3methylimidazolium hexafluorophosphate, 1-Butyl2,3-dimethylimidazolium hexafluorophosphate, 1,3-Diethoxyimidazolium hexafluorophosphate, 1,3-Dimethoxyimidazolium hexafluorophosphate were selected and used for mercury extraction in optimized conditions. Based on results, the extraction efficiency was remarkably affected by amount ionic liquid amount, so it was examined within the range of 20-200 $\mathrm{mg}$. Quantitative extraction was achieved more than $60 \mathrm{mg}$ of

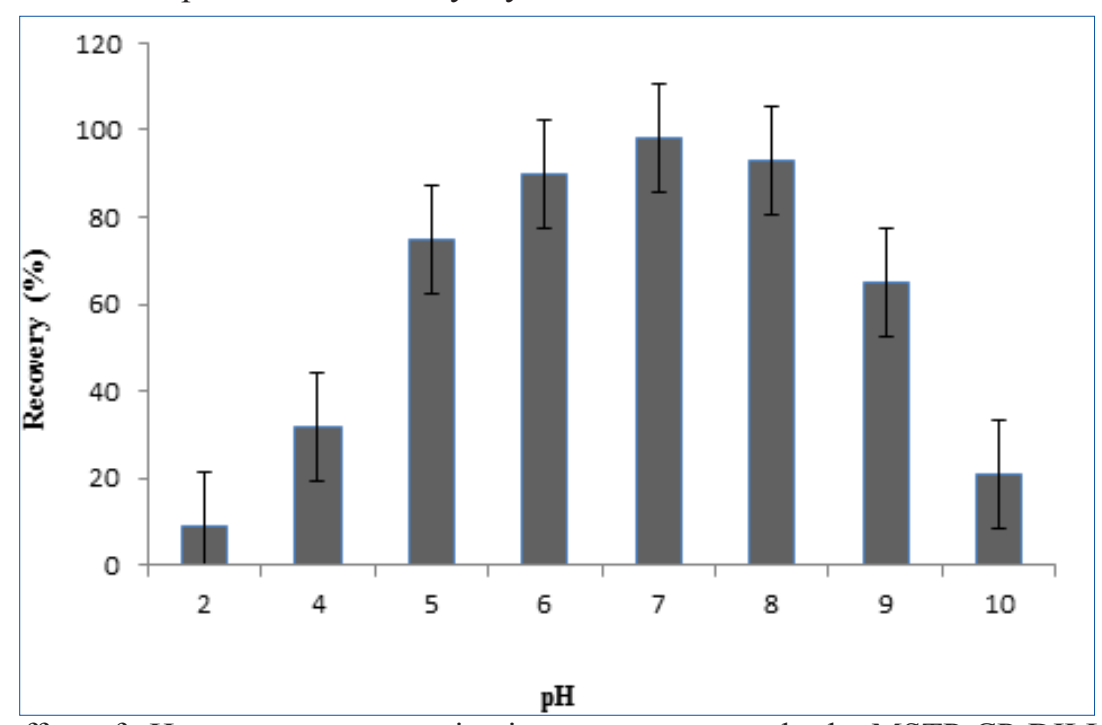

Fig. 2. The effect of $\mathrm{pH}$ on mercury extraction in wastewater samples by MSTP-CP-DILLME method 


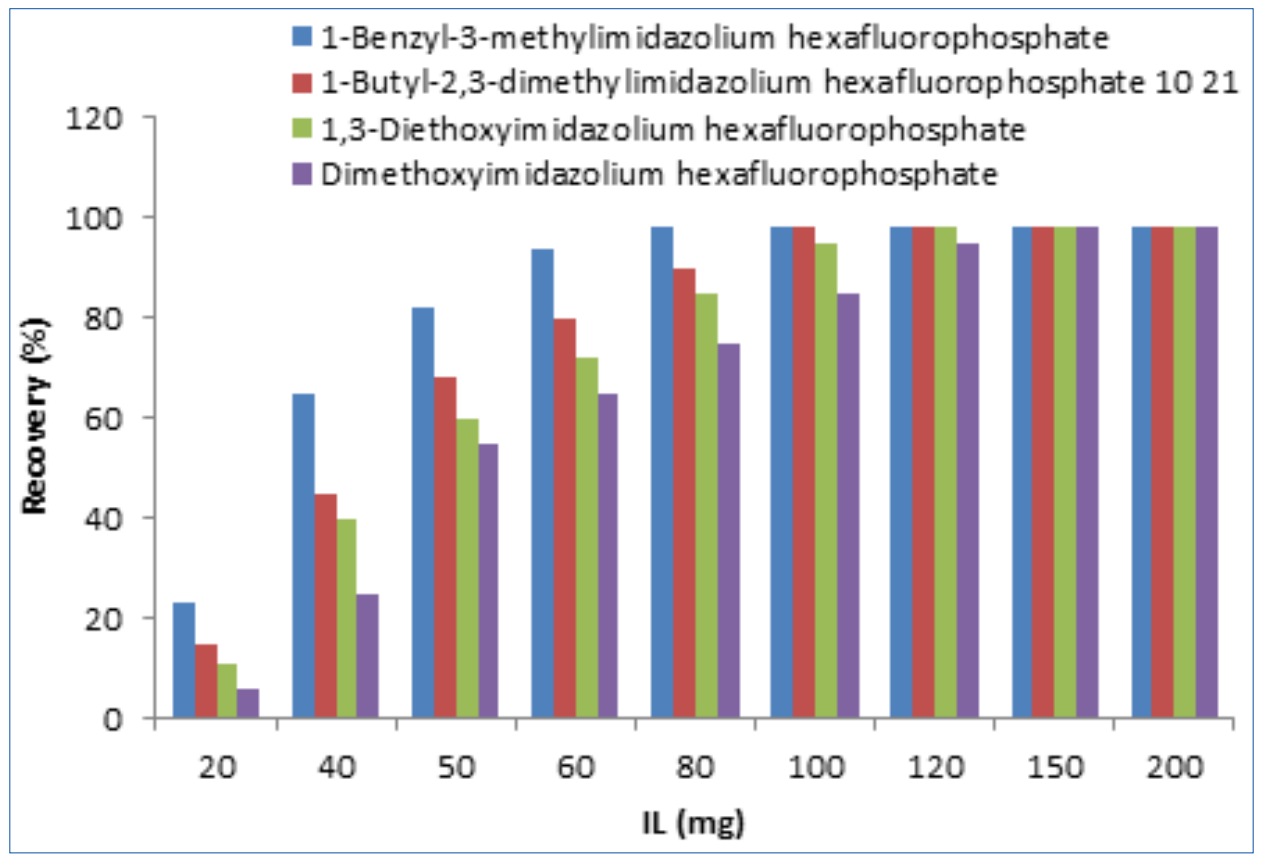

Fig. 3. The effect of different ionic liquids on mercury extraction by MSTP-CP-DILLME method

[BMIM][PF$\left.{ }_{6}\right]$. Therefore, $80 \mathrm{mg}(120 \mu \mathrm{L})$ of $[\mathrm{BMIM}]\left[\mathrm{PF}_{6}\right]$ was chosen as optimum leading to a final IL (Fig. 3).

\subsection{Optimization of amount of MSTP}

The amount of methylsulfanyl thiophenol (MSTP, $\mathrm{C}_{7} \mathrm{H}_{8} \mathrm{~S}_{2}$ ) was evaluated by CP-DLLME. By procedure, The concentration of MSTP between $1.0 \times 10^{-6}$ $50.0 \times 10^{-6} \mathrm{~mol} \mathrm{~L}^{-1}$ was prepared and optimized for maximum extraction mercury in wastewater samples in $\mathrm{pH}=7.0$. The results showed the recovery has high extraction more than $5.7 \times 10^{-6}$ and then no effected on mercury extraction by increasing MSTP. In fact, the $5.7 \times 10^{-6} \mathrm{~mol} \mathrm{~L}^{-1}$ of MSTP was the minimum concentration which was necessary for high recovery for mercury extraction from wastewater samples. So, the $10 \times 10^{-6} \mathrm{~mol} \mathrm{~L}^{-1}$ of MSTP was selected as optimum concentration as interference ions in wastewater and more than the signal remained constant (Fig. 4).

\subsection{Optimization of acids}

The ionic liquids cannot directly use by CV-AAS, because of high viscosity and low interaction with redacting reagents such as NaBH4. By MSTPCP-DILLME procedure, the Hg-MSTP loaded on

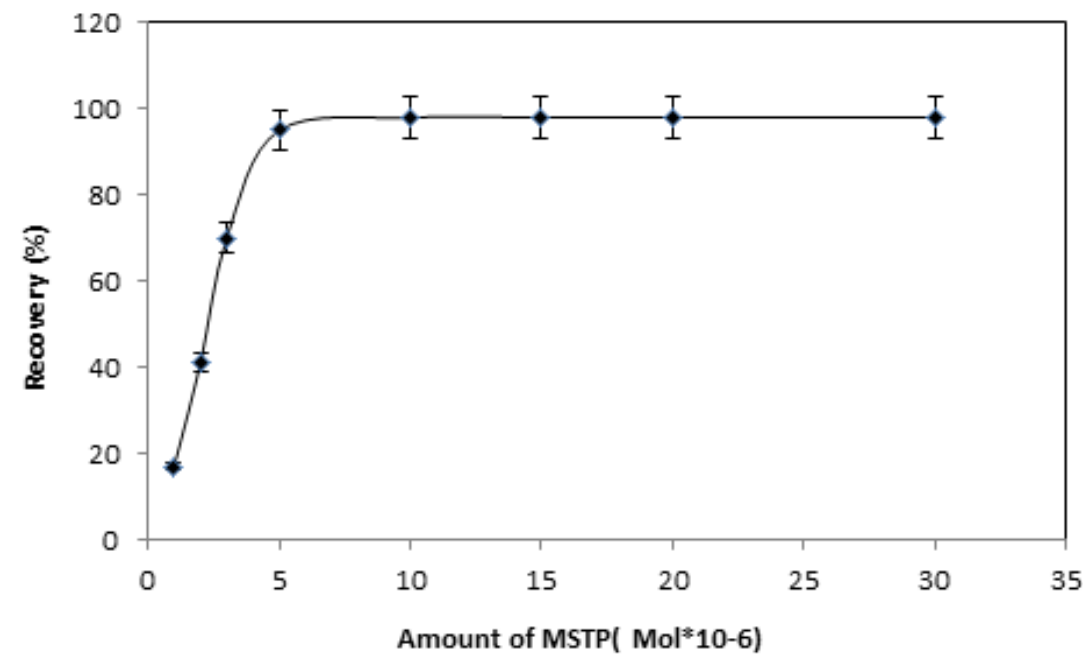

Fig. 4. The effect of MSTP ligand on mercury extraction in wastewater samples by MSTP-CP-DILLME method 
[BMIM][PF6] was back-extraction by the mineral acidic/basic solution. By changing of $\mathrm{pH}$, the covalence bond between sulfur and mercury leads to dissociation and mercury ions release to liquid phase of acid. Different concentration of mineral reagents from $0.1-3 \mathrm{~mol} \mathrm{~L}^{-1}(\mathrm{HCl}, \mathrm{HNO} 3, \mathrm{CH} 3-$ $\mathrm{COOH}, \mathrm{NaOH})$ were used for back-extraction mercury from IL. The results showed that $1.5 \mathrm{~mol}$ $\mathrm{L}^{-1}$ of $\mathrm{HNO}_{3}$ can back-extracted of $\mathrm{Hg}$ (II) from the IL phase. Then, different of volume of reagents between 0.1-1.0 $\mathrm{mL}$ was studied and optimized. The results showed, $0.5 \mathrm{~mL}, 1.5 \mathrm{M}$ of $\mathrm{HNO}_{3}$ had maximum back-extraction mercury in wastewater samples (Fig. 5).

\subsection{Optimization of sample volume}

The different sample volume for extraction mercury was studied. The effect of sample volume was evaluated between 5.0 to $35 \mathrm{~mL}$ of wastewater/ standard samples for $0.0 .5 \mu \mathrm{g} \mathrm{L}^{-1}$ and $6.0 \mu \mathrm{g} \mathrm{L}^{-1}$ of $\mathrm{Hg}(\mathrm{II})$. Quantitative extraction was achieved less than $15 \mathrm{~mL}$. In addition, the higher sample volumes caused to trace soluble the ionic liquid in liquid phase and lead to non-accurate results. So, a sample volume of $10 \mathrm{~mL}$ was selected for further work by CP-DLLME procedure (Fig. 6).

\subsection{Interferences Ions}

For analytical application of the CP-DLLME procedure, the effect of interference of coexisting

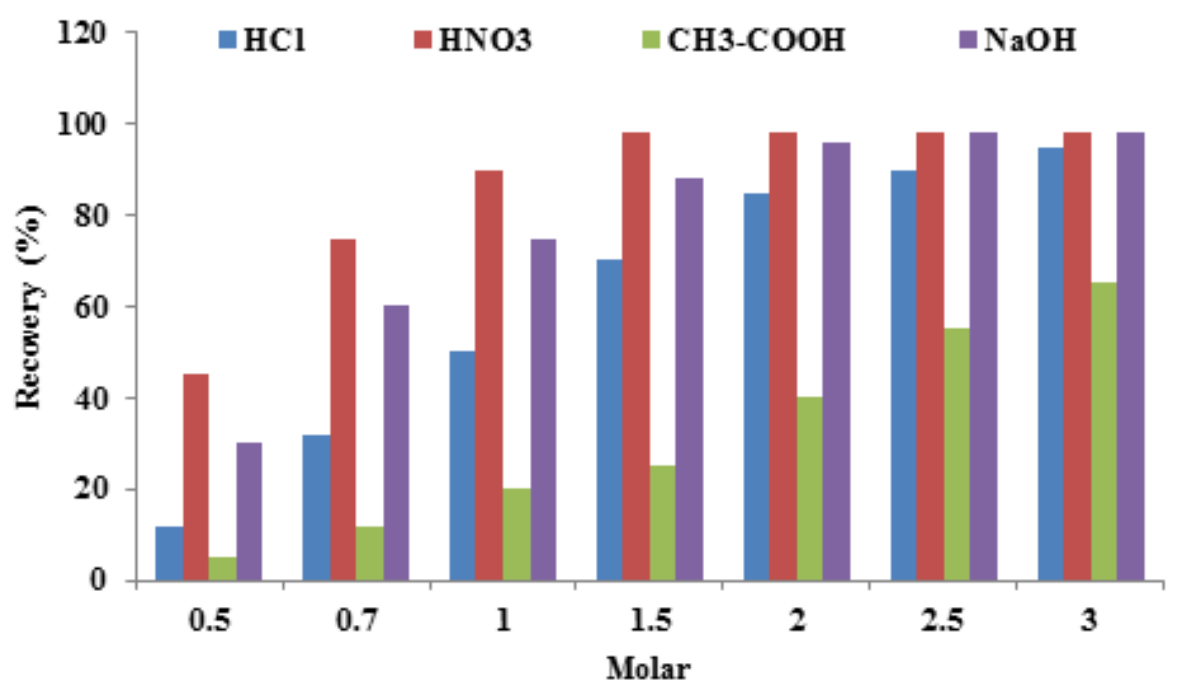

Fig. 5. The effect of different reagents for back-extraction of mercury from MSTP by CP-DILLME method

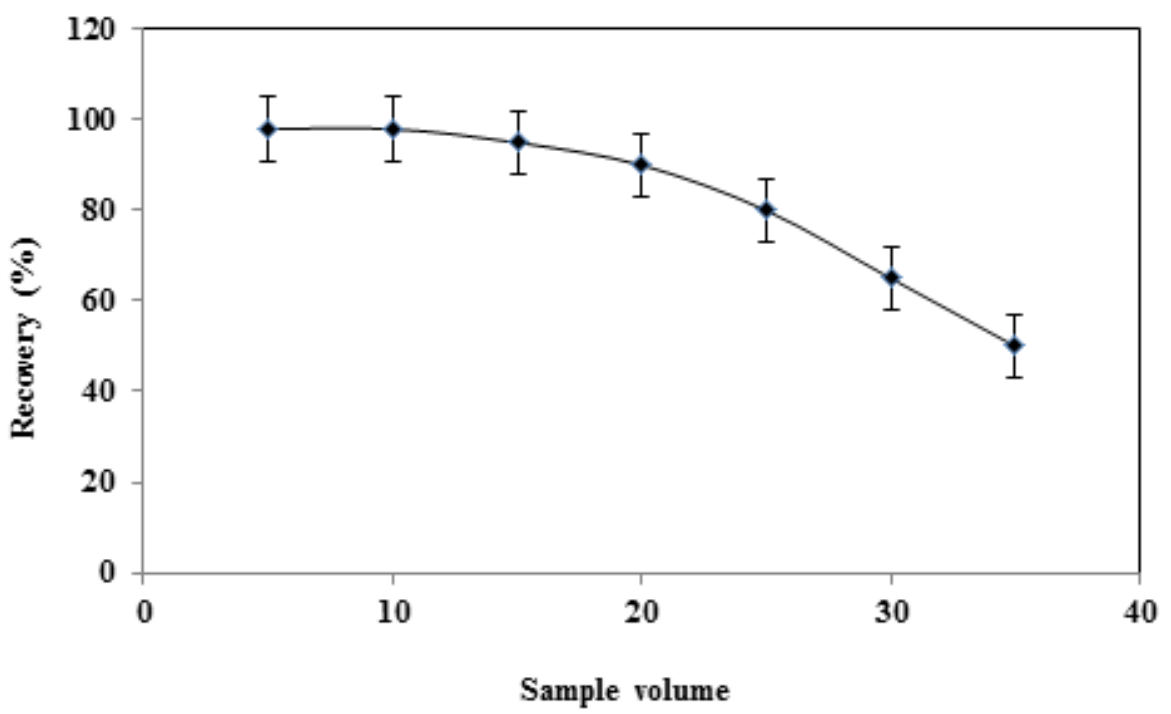

Fig. 6. The effect of sample volume on mercury extraction by MSTP-CP-DILLME method 
Table 3. Effect of interfering ions on the recovery of $\mathrm{Hg}$ (II) ions by CP-DLLME procedure

\begin{tabular}{lcc}
\hline \multicolumn{1}{c}{ Interfering ions $\mathrm{C}_{\mathrm{M}}$} & $\begin{array}{c}\text { Concentration ratio } \\
\left(\mathbf{C}_{\mathrm{M}} / \mathbf{C}_{\mathrm{Hg}^{2+}}{ }^{2+}\right.\end{array}$ & Recovery $(\%)$ \\
\hline $\mathrm{Co}^{2+}, \mathrm{Ni}^{2+}, \mathrm{Pb}^{2+}, \mathrm{Mn}^{2+}, \mathrm{Cd}^{2+}$ & 750 & 98.3 \\
$\mathrm{PO}_{4}^{3-}, \mathrm{CO}_{3}^{2}, \mathrm{NO}_{3}^{-}$, & 1000 & 97.7 \\
$\mathrm{Na}^{+}, \mathrm{K}^{+}, \mathrm{Ca}^{2+}, \mathrm{Mg}^{2+}$ & 900 & 98.4 \\
$\mathrm{Ag}^{+}, \mathrm{Au}^{3+}$ & 40 & 96.5 \\
$\mathrm{Cu}^{2+}, \mathrm{Zn}^{2+}$ & 300 & 97.2 \\
$\mathrm{Cr}^{3+}, \mathrm{As}^{3+}, \mathrm{Fe}^{3+}, \mathrm{Al}^{3+}$ & 500 & 99.3 \\
$\mathrm{~F}-, \mathrm{Cl}-, \mathrm{Br}-, \mathrm{I-}$ & 1100 & 98.8 \\
\hline
\end{tabular}

ions for mercury extraction in wastewater samples was studied. The various amounts of the interfering ions were added to $10 \mathrm{~mL}$ of wastewater sample containing $6.2 \mu \mathrm{g} \mathrm{L}^{-1}$ of $\mathrm{Hg}$ (II). As Table 3, the most of the probable concomitant ions have no considerable effect on the recovery efficiencies of $\mathrm{Hg}$ (II) ions under optimized conditions.

\subsection{Real sample analysis}

The developed CP-DLLME procedure was used for mercury determination in wastewater samples. The results showed the three separate determinations mercury in water samples. The results was verified by spiking of samples with standard concentration of $\mathrm{Hg}$ mercury. Table 4 showed, high recovery (more than 95\%) between the added and found of mercury amount by procedure which confirms the accuracy of the procedure. The recoveries of spiked samples for mercury were ranged from $96 \%$ to
$105 \%$, which demonstrated satisfactory of mercury results. In order to validate the method described, the certified standard reference materials, NISTSRM 1641e (total mercury in water), was analyzed and the results were given in Table 5. The results of the SRM were satisfactorily in agreement with the certified values.

\section{Conclusions}

A simple, fast and sensitive method based on MSTP was used for preconcentration and speciation of mercury in wastewater samples by CP-DILLME procedure. After extraction, the mercury concentration was determined by $\mathrm{CV}$ AAS. The [BMIM][PF6] as ionic liquid was used as trapping agent of MSTP-Hg for rapid separation in short time. Utilizing ionic liquid micelles and MSTP together introduced a CPE procedure based on environmentally friendly for mercury extraction

Table 4. Validation of methodology based on MSTP for mercury analysis by CP-DILLME

\begin{tabular}{lccc}
\hline Sample & Added $\left(\mu \mathrm{gL}^{-1}\right)$ & *Found $\left(\mu \mathrm{gL}^{-1}\right)$ & Recovery $(\%)$ \\
\hline${ }^{a}$ Wastewater Factory & ------- & $0.86 \pm 0.04$ & ------- \\
Wastewater oil & 0.8 & $1.64 \pm 0.62$ & 97.5 \\
& ------- & $1.01 \pm 0.05$ & ------ \\
${ }^{a}$ Wastewater paint & 1.0 & $1.98 \pm 0.09$ & 97.0 \\
& ------- & $1.76 \pm 0.09$ & 101.3 \\
${ }^{a}$ Wastewater Chemical & 1.5 & $3.28 \pm 0.16$ & ------- \\
& ------- & $1.12 \pm 0.06$ & 98.0 \\
Well water & 1.0 & $2.10 \pm 0.11$ & ------ \\
\end{tabular}

${ }^{*}$ Mean of three determinations \pm confidence interval $(\mathrm{P}=0.95, \mathrm{n}=5)$.

a Dilution $(1: 10)$ 
Table 5. Validation of developed CP-DILLME method by standard reference material

\begin{tabular}{|c|c|c|c|c|}
\hline Sample & Certified $\left(\mu \mathrm{g} \mathrm{L}^{-1}\right)$ & $\operatorname{Added}\left(\mu \mathrm{g} \mathrm{L}^{-1}\right)$ & Found $^{\text {a }}\left(\mu \mathrm{g} \mathrm{L^{-1 } )}\right.$ & Recovery (\%) \\
\hline \multirow[t]{3}{*}{$\mathrm{CRM}$} & $1.016 \pm 0.017$ & -------- & $0.986 \pm 0.057$ & ------- \\
\hline & & 0.5 & $1.475 \pm 0.057$ & 97.8 \\
\hline & & 1.0 & $1.971 \pm 0.069$ & 98.5 \\
\hline
\end{tabular}

${ }^{\mathrm{a}}$ Mean of three determinations \pm confidence interval $(\mathrm{P}=0.95, \mathrm{n}=5)$.

${ }^{\mathrm{b}}$ NIST, SRM 1641e, total mercury in water $(\mathrm{p}=0.95)$.

from wastewaters. This procedure provides low LOD values as well as good RSD with quantitative recoveries more than $95 \%$ in optimized conditions. The CP-DILLME procedure based on MSTP and [BMIM][PF6] can be considered as effective sample preparation for mercury extraction from wastewater samples.

\section{References}

[1] M. Tariq, Toxicity of mercury in human: a review, J. Clin. Toxicol., 9 (2019) 9-5.

[2] V.A. Dixit, A simple model to solve a complex drug toxicity problem, Toxicol. Res., 8 (2018) 157-171.

[3] R.A. Bernhoft, Mercury toxicity and treatment: a review of the literature, J. Environ. Public Health, 2012 (2012) 460508.

[4] A.M. Attar, A. Kharkhaneh, M. Etemadifar, K. Keyhanian, V. Davoudi, M. Saadatnia, Serum mercury level and multiple sclerosis, Biol. Trace Elem. Res., 146 (2012) 150-153.

[5] A. M. Al-Ghouti, D. Da'ana, M. Abu-Dieyeh, M. Khraisheh, Adsorptive removal of mercury from water by adsorbents derived from date pits. Sci. Reports, 9 (2019) 15327.

[6] S.E. Schober, T.H. Sinks, R.L. Jones, P.M. Bolger, M. McDowell, J. Osterloh, E.S. Garrett, R.A. Canady, C.F. Dillon, Y. Sun, Blood mercury levels in US children and women of childbearing age, JAMA, 289 (2003) 1667-1674.

[7] S. Santana Lins, C. Francisco Virgens, W. Nei Lopes dos Santos, I. Helena Santos Estev, Online solid phase extraction system using an ion imprinted polymer based on dithizone chelating for selective preconcentration and determination of mercury in natural waters by CV AFS, Microchem. J., 150 (2019) 104075.

[8] Y. Hui, Y. Liu, W C. Tang, Determination of mercury(II) on a centrifugal microfluidic device using ionic liquid dispersive liquid-liquid microextraction, Micromachin., 10 (2019) 523.

[9] Y.M. Liu, F.P. Zhang, B.Y. Jiao, J.Y. Rao, G. Leng, Automated dispersive liquid-liquid microextraction coupled to high performance liquid chromatography-cold vapor atomic fluorescence spectroscopy for the determination of mercury species in natural water samples, J. Chromatogr., A 1493(2017) 1-9.

[10] M. Mei, X. Huang, X. Yang, Q. Luo, Effective extraction of triazines from environmental water samples using magnetismenhanced monolith-based in-tube solid phase microextraction, Anal. Chim. Acta, 937( 2016) 69-79.

[11] I. López-García, Y. Vicente-Martínez, M. Hernández-Córdoba,Non-chromatographic speciation of chromium at sub-ppb levels using cloud point extraction in the presence of unmodified silver nanoparticles, Talanta, 132 (2015) 23-28.

[12] M. Sajid, Dispersive liquid-liquid microextraction coupled with derivatization: A review of different modes, applications, and green aspects. TrAC Trends Anal. Chem., 106 (2018) 169-182.

[13] M. Tuzen, O. Z. Pekiner, Ultrasound-assisted ionic liquid dispersive liquid-liquid microextraction combined with graphite furnace atomic absorption spectrometric for selenium speciation in foods and beverages, Food Chem., 188 (2015) 619-624.

[14] H. Shirkhanloo, M. Ghazaghi, M. M. Eskandari, Cloud point assisted dispersive ionic liquid -liquid microextraction for chromium speciation in human blood samples based on isopropyl 2-[(isopropoxycarbothiolyl)disulfanyl] ethane thioate, Anal. Chem. Res., 10 (2016) 18-27.

[15] L. Kocurov, I. S. Balogh, J. Sandrejov, V. Andruch, Recent advances in dispersive liquid-liquid microextraction using organic solvents lighter than water, A review, Microchem. J., 102 (2012) 11-17.

[16] S.P.M. Ventura, F.A. E Silva, M.V. Quental, D. Mondal, M.G. Freire, J.A.P. Coutinho, Ionic-liquidmediated extraction and separation processes for 
bioactive compounds: past, present, and future trends, Chem. Rev., 117 (2017) 6984-7052.

[17] S. M. Mostafavi, M. Adibi, F. Pashaee, M. Piryaei, Modification of glassy carbon electrode by a simple, inexpensive and fast method using an ionic liquid based on immidazolium as working electrode in electrochemical determination of some biological compounds, Asian J. Chem., 23 (2011) 5247-5252.

[18] S. M. Mostafavi, M. Adibi, F. Pashaee, M. Piryaei, Electrochemical Investigation of Thiophene on Glassy Carbon Electrode and Quantitative Determination of it in Simulated Oil Solution by Differential Pulse Voltammetry and Amperometry Techniques. Asian J. Chem., 23 (2011) 5356-5360.

[19] H. Zheng, J. Hong, X. Luo, S. Li, M. Wang, Combination of sequential cloud point extraction and hydride generation atomic fluorescence spectrometry for preconcentration and determination of inorganic and methyl mercury in water samples, Microchem. J. 145 (2019) 806-812.

[20] S.L.C. Ferreira,V.A. Lemos, L.O.B. Silva, A.F.S. Queiroz, A.S. Souza, E.G.P. da Silva, W.N.L. dos Santos, C.F. das Virgens, Analytical strategies of sample preparation for the determination of mercury in food matrices, A review, Microchem. J., 121 (2015) 227-236.

[21] A. Badamchi Shabestari, M. Shekarchi, S. M. Mostafavi, Development of environmental analysis for determination of total mercury in fish oil pearls by microwave closed vessels digestion coupled with ICP-OES, Ekoloji, 27 (2018) 1935-1943.

[22] S.M. Mostafavi, Mercury determination in work place air and human biological samples based on dispersive liquid-liquid micro-extraction coupled with cold vapor atomic absorption spectrometry, Anal. Method. Environ. Chem. J., 2 (2019) 49-58.

[23] K. Seebunrueng, Y. Santaladchaiyakit, S. Srijaranai, Vortex-assisted low density solvent liquid-liquid microextraction and salt-induced demulsification coupled to high performance liquid chromatography for the determination of five organophosphorus pesticide residues in fruits, Talanta, 132 (2015) 769-774.

[24] S. M. Mostafavi, A. A. Miranbeigi, Handbook of mineral analysis. Mani publication, Ltd, 2012.

[25] G. D’Orazio, M. Asensio-Ramos, J. HernandezBorges, M. A. Rodriguez-Delgado, S. Fanali, Evaluation of the combination of a dispersive liquid-liquid microextraction method with micellar electrokinetic chromatography coupled to mass spectrometry for the determination of estrogenic compounds in milk and yogurt, Electrophoresis, 36 (2015) 615-625.

[26] K.D. Danov, P.A. Kralchevsky, K.P. Ananthapadmanabhan, Micelle-monomer equilibria in solutions of ionic surfactants and in ionic-nonionic mixtures: A generalized phase separation model, Adv. Colloid Interfac. Sci., 206 (2014) 17-45.

[27] T.P. Nguyen, P. Hesemann, T.M.L. Tran, J.J.E. Moreau, Nanostructured polysilsesquioxanes bearing amine and ammonium groups by micelle templating using anionic surfactants, J. Mater. Chem. 20 (2010) 3910-3917.

[28] JYuan, A. Li, T. Chen, J. Du, J. Pan, Micelle dominated distribution strategy for non-matrix matched calibration without an internal standard, Anal. Chim. Acta, 1102 (2019) 24-35. 